\title{
The Use of High-Flow Nasal Cannula Oxygen Outside the ICU
}

\author{
Sasson Zemach, Yigal Helviz, Michal Shitrit, Reuven Friedman, and Phillip D Levin
}

BACKGROUND: High-flow nasal cannula (HFNC) oxygen therapy is a routine, evidence-based treatment in the ICU. Due to its ease of application, non-evidence-based use of HFNC has spread to non-ICU wards. This study reports on the experience with HFNC outside the ICU. METHODS: This is an observational study of HFNC prescribed by treating physicians in non-ICU areas. Primary outcomes included change in dyspnea visual analog scale score and physiological variables both before and $30 \mathrm{~min}$ after initiation of HFNC treatment. Secondary outcomes included mortality, ICU admission, and intubation. RESULTS: We observed decreased median (interquartile range) visual analog scale scores after initiation of HFNC: $8(6-9)$ versus $5(4-6)(P<.001)$ in 90 of 111 subjects $(81 \%, 95 \%$ CI $72.5-87.9 \%, P<.001)$. Breathing frequency $(31 \pm 10$ vs $26 \pm 7$ breaths $/ \mathrm{min}$, $P<.001)$ and saturation $(84 \pm 12 \%$ vs $94 \pm 5 \%, P<.001)$ also improved. Overall cohort mortality was 55 of 111 subjects $(50 \%)$; however, 41 of 111 subjects (33\%) had a do not resuscitate (DNR) order. Among 70 non-DNR subjects, early mortality $(<72$ h) occurred in 9 of 70 subjects $(13 \%)$, and late mortality in 12 of 70 subjects $(17 \%)$. The composite end point (ie, discharged alive, non-intubated, not admitted to ICU) was met by 35 of 70 subjects (50\%) without a DNR order. An increased ROX index ( $\left[\mathrm{S}_{\mathrm{pO}_{2}} / \mathrm{F}_{\mathrm{IO}_{2}}\right] /$ breathing frequency) was the only independent predictor associated with achieving the composite outcome (odds ratio $1.51,95 \% \mathrm{CI}$ 1.1-2.0, $P=.01$ ). Higher pre-connection visual analog scale score (odds ratio $1.75,95 \% \mathrm{CI}$ $1.35-2.28, P<.001$ ) and a history of respiratory disease (odds ratio 3.52, 95\% CI 1.27-9.72, $P=.01$ ) were predictors of greater improvement in dyspnea with HFNC. No variable predicted mortality. CONCLUSIONS: HFNC outside the ICU was associated with improved visual analog scale score, breathing frequency, and saturation but with a relatively high mortality, even in non-DNR subjects. HFNC was used in many subjects who had a DNR order. This therapy may have been palliative in intent. Care should be exercised in using this therapy in a setting that is not continuously monitored. Key words: HFNC; respiratory failure; medical ward; ICU; non invasive ventilation; outcome; oxygen therapy. [Respir Care 2019;64(11):1333-1342. (C) 2019 Daedalus Enterprises]

Introduction

High-flow nasal cannula (HFNC) oxygen therapy has an increasing role as an effective noninvasive therapy for patients with respiratory failure in ICUs. ${ }^{1-5}$ The technology is based on flow of up to $60 \mathrm{~L} / \mathrm{min}$ of an

\footnotetext{
Drs Zemach, Helviz, and Levin are affiliated with the General Intensive Care Unit, Shaare Zedek Medical Center, Jerusalem, Israel. Ms Shitrit is affiliated with the Respiratory Therapy Unit, Shaare Zedek Medical Center, Jerusalem, Israel. Dr Friedman is affiliated with the Geriatrics Unit, Shaare Zedek Medical Center, Jerusalem, Israel.
}

The authors have disclosed no conflicts of interest. air/oxygen mixture through a heater/humidifier to a widebore nasal cannula. The high flow generates low PEEP and decreases dead space. ${ }^{6}$ In contrast to noninvasive ventilation delivered through a mask, there is limited support of carbon dioxide elimination, ${ }^{7}$ however the nasal cannula is much more comfortable than a tightly applied face mask. ${ }^{8,9}$

Correspondence: Yigal Helviz MD, General Intensive Care Unit, Shaare Zedek Medical Center, Jerusalem 9103102, Israel. E-mail: yigalhe@szmc.org.il.

DOI: $10.4187 /$ respcare.06611 
HFNC therapy has been shown to be superior to traditional oxygenation support tools (eg, low-flow nasal cannula, face mask) in improving respiratory indices such as breathing frequency, oxygen saturation, and dyspnea ${ }^{10}$ and compares well to noninvasive mask ventilation in certain circumstances. ${ }^{1,11,12}$ These findings are supported by metaanalyses ${ }^{13}$ but are not universal. ${ }^{14-16}$

See the Related Editorial on Page 1447

The ease of use, apparent lack of complications, and success in therapy have led to the use of HFNC beyond the ICU. However, use of HFNC in other settings is not based on evidence and has not been widely evaluated. In this study we examine use of HFNC outside the ICU to identify the patients chosen, effectiveness of therapy, and patient outcomes.

\section{Methods}

We performed a prospective observational study of subjective and objective measures of dyspnea obtained before and after administration of HFNC to patients with hypoxemic respiratory failure outside the ICU. The study included consecutive adult subjects for whom treating physicians decided to administer HFNC in the medical division (including general medical, intermediate medical units, geriatrics, and hemato-oncology wards) as well as the emergency department of the Shaare Zedek Medical Center, a 750-bed academic tertiary referral center in Jerusalem, Israel. The hospital ethics committee waived the requirement for informed consent (0104-15-SZMC) because the study was observational. The decision to administer HFNC was not part of the study protocol, being at the sole discretion of the treating physicians. Vital signs were collected as part of routine clinical care, and additional subject participation was limited to providing a subjective measure of dyspnea before and after administration of HFNC via the visual analog scale score for dyspnea. Patients under 18 y old, pregnant women, patients with tracheostomy, or patients who had received prior treatment with HFNC were excluded.

Subjective and objective measures were recorded immediately prior to administration of HFNC and $30 \mathrm{~min}$ later by the respiratory therapist applying the therapy. The subjective measure of dyspnea was evaluated using a visual analog scale score as an ordinal scale. Subjects were asked to describe the degree of their shortness of breath and assign a value ranging from 0 (no distress) to 10 (worst distress possible). While this is not a true visual analog scale measurement of symptom severity, we used this term for simplicity. Objective physiological variables included pulse, blood pressure, breathing frequency, and

\section{QUICK LOOK}

\section{Current knowledge}

The use of high-flow nasal cannula (HFNC) to deliver oxygen therapy has been investigated mainly in monitored environments such as ICUs, emergency departments, and post-anesthesia care units. HFNC has been reported to improve patient comfort and physiological measures, and to be associated with minimal complications.

\section{What this paper contributes to our knowledge}

The application of HFNC oxygen to subjects with continued hypoxemia despite oxygen therapy by traditional means in minimally monitored beds in medical and geriatric wards was associated with improved visual analog scale scores and physiological measures in all subgroups examined. HFNC use was associated with high mortality, particularly in subjects with a do not resuscitate order. Among other subjects, mortality was similar to expected.

oxygen saturation measured using pulse oximetry. Demographic, medical, and outcome data were obtained from the medical record.

\section{Data Analysis}

The primary outcome measures of effectiveness were changes in visual analog scale score, pulse, blood pressure, breathing frequency, and oxygen saturation after initiation of treatment. Secondary outcomes included mortality, ICU admission, and intubation. A composite outcome measure of treatment success was defined as subjects who survived to hospital discharge, were not admitted to ICU, and were not intubated. The ROX index $\left(\left[\mathrm{S}_{\mathrm{pO}_{2}} / \mathrm{F}_{\mathrm{IO}_{2}}\right] /\right.$ breathing frequency) at $30 \mathrm{~min}$ after administration of HFNC oxygen was calculated for subjects meeting or failing the composite outcome measure. ${ }^{17,18}$

\section{Subgroup Analysis}

Survivors were compared to non-survivors after exclusion of subjects with a do not resuscitate (DNR) order to identify risk factors for mortality. Mortality was divided into early mortality ( $\leq 72 \mathrm{~h}$ after application of HFNC), and late mortality ( $>72 \mathrm{~h}$ after application of HFNC). The term "DNR order" is used as a generic term to include all orders to limit initiation of therapies including intubation and cardiopulmonary resuscitation. Outcomes were also compared for subjects with and without a DNR order. 
Subjects who reported improved visual analog scale scores were compared to those without improvement in an attempt to identify factors associated with benefit from HFNC therapy. The median improvement in visual analog scale score was identified from the whole study population. The population was then divided into 2 groups: those with a decrease in visual analog scale score that was greater than the median change (improved $\Delta$ visual analog scale group), and those with a change in visual analog scale less than or equal to the median change (unimproved $\Delta$ visual analog scale group). Therapy and subject outcomes were also compared according to the composite outcome measure (ie, no intubation, no ICU admission, and hospital discharge alive).

Sample size was estimated from prospective preliminary data. Assuming $90 \%$ of subjects reported improved visual analog scale scores, as was reported in an unpublished preliminary study, a power analysis (using Fisher exact test) calculated that a sample of 120 subjects would be sufficient to demonstrate improved dyspnea (95\% CI 83.2-94.7\%).

Changes in visual analog scale were analyzed with the Wilcoxon test. Changes in physiological measures per subject were analyzed using the paired $t$ test. Differences between group means were compared using the $t$ test. Qualitative variables were compared using the chi-square test or Fisher exact test. Multivariate logistic regression was used to identify predictors of improvement in visual analog scale scores. The population was divided into 2 groups (ie, improved visual analog scale vs unimproved visual analog scale), and variables present prior to connection, which were measured for $>10$ subjects and associated with improvement at $P<.1$ (pre-connection visual analog scale score and past medical history of respiratory failure) were included as explanatory variables. Logistic regression was also used to identity independent predictors of the composite outcome measure in non-DNR subjects including age, ROX index, $\Delta$ visual analog scale, and length of stay prior to starting HFNC therapy as predictor variables. Multiple collinearity was investigated using a correlation matrix, tolerance, variance inflation, and colinearity index. No collinearity was identified in either analysis. All analyses were performed using SAS 9.2 (SAS Institutes, Cary, North Carolina); all tests were 2-tailed, and significance was defined as $P<.05$.

\section{Results}

Data were collected on 176 HFNC administrations from December 2015 to December 2017. Exclusion criteria were present on 7 occasions, and visual analog scale scores were not adequately recorded on 58 occasions, leaving 111 events for analysis. Mean length of stay prior to HFNC therapy was $7 \pm 10 \mathrm{~d}$, and mean duration of therapy was $93 \pm 124 \mathrm{~h}$.

\section{Primary Outcomes}

After initiation of HFNC treatment, 90 of 111 subjects $(81 \%, 95 \%$ CI $72.5-87.9 \%, P<.001)$ reported improved dyspnea with decreased visual analog scale scores: preHFNC median (interquartile range [IQR]) visual analog scale score was 8 (6-9) vs median (IQR) post-HFNC score of 5 (4-6), $P<.001$. Visual analog scale scores decreased significantly in most etiology subgroups. In parallel, pulse and breathing frequency decreased significantly, and oxygen saturation significantly increased (Table 1).

\section{Secondary Outcomes}

Of the 111 subjects treated with HFNC, 55 (50\%) died, $24(22 \%)$ within $72 \mathrm{~h}$ of beginning HFNC (ie, early mortality) and 31 (28\%) later (ie, late mortality). However, 41 of $111(33 \%)$ subjects in the cohort had a DNR order, of whom 38 of $41(93 \%)$ died. Among the 70 subjects without a declared DNR order, overall mortality was 18 of 70 (26\%): early mortality for 9 of $70(13 \%)$; late mortality for 9 of 70 (13\%). The mean time from starting HFNC to death was $7.2 \pm 8.6 \mathrm{~d}$. Mortality ranged from 8 of $46(17 \%)$ in the internal medicine ward to 5 of $11(45 \%)$ in the hemato-oncology ward.

Among subjects without a DNR order, 13 of 70 (19\%) subjects were admitted to ICU ( 9 subjects $\leq 72 \mathrm{~h}$, and 4 subjects $>72 \mathrm{~h}$ after beginning HFNC; mean time from starting HFNC to ICU admission was $2.1 \pm 2.9 \mathrm{~d}$ ), and 18 of $70(26 \%)$ subjects were intubated $(12$ subjects $\leq 72 \mathrm{~h}$, and 6 subjects $>72 \mathrm{~h}$, with a mean time to intubation of $4.2 \pm 7.6 \mathrm{~d})$.

\section{Subgroup Analyses}

Composite Outcome Measure. Overall, 35 of 70 (50\%) subjects without a DNR order met the composite outcome measure for successful treatment (ie, no ICU admission, no intubation, and survival to hospital discharge) (Table 2). Among these subjects, the ROX index was calculated as $\mathrm{S}_{\mathrm{pO}_{2}} / \mathrm{F}_{\mathrm{IO}_{2}}$ /breathing frequency. The ROX index has been used to predict the success of HFNC therapy, with a higher score indicating a higher probability of successful therapy. ${ }^{17,18}$ The score was $8.2 \pm 3.6$ for subjects with successful therapy versus $5.1 \pm 1.9, P<.001$ for subjects with unsuccessful therapy (ie, subject was admitted to ICU, was intubated, or died during admission). Multivariate analysis, with time from admission to HFNC, change in visual analog scale score, ROX index, and age as predictor variables, showed that only increasing ROX index was asso- 
Table 1. Visual Analog Scale Scores for Dyspnea and Physiological Variables Before and After HFNC Therapy

\begin{tabular}{|c|c|c|c|c|c|}
\hline & $n$ & Before HFNC Therapy & After HFNC Therapy & Mean Difference (paired data) & $P$ \\
\hline \multicolumn{6}{|l|}{ Visual Analog Scale Scores } \\
\hline Whole population & 111 & $8(6-9)$ & $5(4-6)$ & $-2(-4$ to -1$)$ & $<.001$ \\
\hline \multicolumn{6}{|l|}{ By hypoxia etiology* } \\
\hline Pneumonia & 66 & $7.5(6-8.5)$ & $5(4-6)$ & $-2(-4$ to -1$)$ & $<.001$ \\
\hline Sepsis & 25 & $8(6-10)$ & $5(4-6)$ & $-2(-4$ to -1$)$ & $<.001$ \\
\hline Congestive heart failure & 25 & $8(6-8)$ & $4(4-6)$ & $-2(-5$ to -1$)$ & $<.001$ \\
\hline Malignancy & 18 & $8(6-9)$ & $6(4-6)$ & $-2(-4$ to 0$)$ & $<.001$ \\
\hline Restrictive lung disease & 8 & $6.5(5.5-9)$ & $4(2-5.5)$ & $-3.5(-6$ to -1$)$ & .031 \\
\hline COPD & 5 & $10(8-10)$ & $2(2-5)$ & $-5(-6$ to -4$)$ & .062 \\
\hline \multicolumn{6}{|l|}{ Physiological Variables } \\
\hline Pulse, beats/min & & $97.4 \pm 22.5$ & $93.2 \pm 19.6$ & $-4.6 \pm 13.7$ & .002 \\
\hline \multicolumn{6}{|l|}{ Blood pressure, $\mathrm{mm} \mathrm{Hg}$} \\
\hline Systolic & & $120.0 \pm 26.2$ & $117.6 \pm 22.8$ & $-2.5 \pm 17.1$ & .18 \\
\hline Diastolic & & $68.1 \pm 15.3$ & $67.2 \pm 12.5$ & $-0.5 \pm 14.0$ & .75 \\
\hline Oxygen saturation, $\%$ & & $84.1 \pm 12.3$ & $93.7 \pm 4.9$ & $9.4 \pm 11.2$ & $<.001$ \\
\hline Breathing frequency, breaths/min & & $30.6 \pm 9.7$ & $25.8 \pm 7.2$ & $-5.6 \pm 7.1$ & .001 \\
\hline \multicolumn{6}{|c|}{$\begin{array}{l}\text { Visual analog scale scores presented as median (interquartile range). Physiological data are presented as mean } \pm \text { SD. Change data represent mean of paired change. } \\
\text { * Overlap exists between etiologies. } \\
\text { HFNC }=\text { high-flow nasal cannula }\end{array}$} \\
\hline
\end{tabular}

ciated with improved probability of successful therapy (odds ratio $[\mathrm{OR}] 1.51,95 \% \mathrm{CI} 1.10-2.07, P=.01$ ).

Mortality. None of the demographic, etiological, or physiological variables recorded were associated with survival status in subjects without a DNR order (Table 3).

Improved Visual Analog Scale. The median difference between visual analog scale scores before and after initiation of treatment ( $\Delta$ visual analog scale) was -2 (Table 4). Multivariate analysis using visual analog scale score prior to HFNC administration and past medical history of respiratory disease as predictor variables indicated that both of these variables were predictors of improved visual analog scale (pre-HFNC administration visual analog scale score: OR 1.75, 95\% CI 1.35-2.28, $P<.001$; past history of respiratory disease OR $3.52,95 \% \mathrm{CI} 1.27-9.72, P=.01$ ).

Subjects With a DNR Order. Visual analog scale scores improved similarly for subjects with DNR orders and subjects without DNR orders: median change (IQR) in visual analog scale scores subjects with vs without a DNR order was $-2(-3.5$ to -1.0$)$ versus $-2(-4$ to -1$), P=.49$ (Table 5).

\section{Missing Data}

A comparison of basic demographics and outcomes for subjects for whom data were not collected with the 111 subjects with adequate study data revealed similar results (age $70 \pm 19$ vs $75 \pm 17 \mathrm{y}, P=.14$; male sex $55 \%$ vs $50 \%, P=.57$; and overall mortality $50 \%$ vs $44 \%, P=.35)$.

\section{Discussion}

The use of HFNC outside the ICU is effective, in that its use is associated with a decrease in the severity of dyspnea in the large majority of subjects (81\%) and improved physiological parameters. Further, $50 \%$ of the non-DNR subjects included in the cohort met the composite success outcome measure of no intubation, no ICU admission, and survival to hospital discharge. The safety of the therapy was initially of significant concern in view of the high overall mortality $(50 \%)$. However, it was discovered that a large proportion (33\%) of the cohort were subject to DNR orders, and that early mortality ( $<72 \mathrm{~h}$ after commencing therapy) among non-DNR subjects was considerably lower (13\%), which was somewhat reassuring. No pretreatment parameters were significant predictors of mortality, although worse dyspnea (as measured by a higher pre-administration visual analog scale score) and the presence of preexisting respiratory disease were both significant predictors of efficacy (as measured by a decrease in visual analog scale of dyspnea). Immediate physiological improvement (improved ROX index at $30 \mathrm{~min}$ ) was a significant predictor of good outcome (achievement of the composite outcome measure - no ICU admission, no intubation and survival to hospital discharge).

Very few studies have been performed on HFNC outside of the ICU. A study on subjects with cardiogenic 


\section{HFNC OUTSIDE THE ICU}

Table 2. Comparison of Subjects Grouped by Composite Outcome Measure Among Non-DNR Subjects

\begin{tabular}{|c|c|c|c|c|c|}
\hline & \multirow{2}{*}{ Composite Success } & \multirow{2}{*}{ Composite Failed } & \multirow{2}{*}{$P$} & \multicolumn{2}{|c|}{ Multivariate Analysis } \\
\hline & & & & Odds Ratio $(95 \% \mathrm{CI})$ & $P$ \\
\hline Subjects, $n(\%)$ & $35(50)$ & $35(50)$ & & & \\
\hline Male sex, $n(\%)$ & $19(54)$ & $14(40)$ & .23 & & \\
\hline Age, y & $77 \pm 17$ & $70 \pm 15$ & .10 & $1.02(0.97-1.07)$ & .42 \\
\hline \multicolumn{6}{|l|}{ Medical Background* } \\
\hline Cardiovascular & $20(57)$ & $19(54)$ & .81 & & \\
\hline Respiratory & $5(14)$ & $10(29)$ & .14 & & \\
\hline Hypertension & $22(63)$ & $20(57)$ & .63 & & \\
\hline Diabetes mellitus & $14(40)$ & $12(34)$ & 62 & & \\
\hline Malignancy & $5(14)$ & $5(14)$ & .99 & & \\
\hline Active smoker & $5(14)$ & $6(17)$ & .74 & & \\
\hline $\mathrm{CO}_{2}$ retention per history & $23(68)$ & $21(64)$ & .73 & & \\
\hline \multicolumn{6}{|l|}{ Etiology of Respiratory Failure* } \\
\hline Pneumonia & $21(60)$ & $24(69)$ & .45 & & \\
\hline Congestive heart failure & $6(17)$ & $9(26)$ & .38 & & \\
\hline Malignancy & $3(9)$ & $2(6)$ & .64 & & \\
\hline Sepsis & $10(29)$ & $6(17)$ & .25 & & \\
\hline COPD & $2(6)$ & $3(9)$ & 64 & & \\
\hline Other lung disease & $2(6)$ & $2(6)$ & .99 & & \\
\hline \multicolumn{6}{|l|}{ Vital Signs and Physical Data } \\
\hline Fever & $24(69)$ & $27(79)$ & .30 & & \\
\hline Bacteremia & $4(12)$ & $3(10)$ & .94 & & \\
\hline Pulse before HFNC & $91 \pm 22$ & $99 \pm 21$ & .18 & & \\
\hline Systolic before HFNC & $118 \pm 23$ & $115 \pm 29$ & 65 & & \\
\hline Diastolic before HFNC & $68 \pm 12$ & $65 \pm 16$ & .38 & & \\
\hline Breathing frequency before HFNC & $28 \pm 10$ & $31 \pm 10$ & .43 & & \\
\hline $\mathrm{S}_{\mathrm{pO}_{2}}$ before $\mathrm{HFNC}$ & $87 \pm 8$ & $83 \pm 11$ & .09 & & \\
\hline Visual analog scale before HFNC & $7(5-9)$ & $8(6-9)$ & 67 & & \\
\hline$\Delta$ Pulse & $-5 \pm 11$ & $-2 \pm 15$ & .46 & & \\
\hline$\Delta$ Systolic blood pressure & $0 \pm 13$ & $2.4 \pm 18$ & .56 & & \\
\hline$\Delta$ Diastolic blood pressure & $-1 \pm 11$ & $2 \pm 19$ & .61 & & \\
\hline$\Delta$ Breathing frequency & $-6 \pm 8$ & $-5 \pm 7$ & .59 & & \\
\hline$\Delta$ Oxygen saturation & $8 \pm 8$ & $9 \pm 9$ & .67 & & \\
\hline$\Delta$ Visual analog scale & $-4(-5$ to -2$)$ & $-2(-3$ to 0$)$ & .003 & $0.84(0.62-1.15)$ & .27 \\
\hline ROX Index & $8.2 \pm 3.6$ & $5.1 \pm 1.9$ & $<.001$ & $1.51(1.10-2.07)$ & .01 \\
\hline \multicolumn{6}{|l|}{ Treatment and Hospitalization } \\
\hline Initial $\mathrm{F}_{\mathrm{IO}_{2}}$ & $0.68 \pm 0.22$ & $0.79 \pm 0.19$ & .02 & & \\
\hline Initial gas flow, $\mathrm{L} / \mathrm{min}$ & $45 \pm 8$ & $47 \pm 9$ & .19 & & \\
\hline Duration of HFNC, h & $95 \pm 92$ & $67 \pm 129$ & .30 & & \\
\hline Length of stay, d & $18 \pm 10$ & $34 \pm 42$ & .046 & & \\
\hline Admission to HFNC, $\mathrm{d}$ & $5 \pm 6$ & $8 \pm 9$ & .08 & $0.94(0.84-1.05)$ & .29 \\
\hline HFNC to discharge, $\mathrm{d}$ & $13 \pm 7$ & $26 \pm 41$ & .10 & & \\
\hline $\begin{array}{l}\text { The composite outcome measure for successful the } \\
\text { (interquartile range). } \\
\text { * Overlap exists between etiologies. } \\
\text { DNR }=\text { do not resuscitate order } \\
\mathrm{HFNC}=\text { high-flow nasal cannula } \\
\Delta=\text { difference between first and second measurem } \\
\mathrm{ROX}=\text { ratio of } \mathrm{S}_{\mathrm{pO}_{2}} / \mathrm{F}_{\mathrm{IO}_{2}} \text { to breathing frequency }\end{array}$ & luded no intubation, no ICU & n, and hospital discharge & are present & ean $\pm \mathrm{SD}$, frequency $(\%)$, or me & \\
\hline
\end{tabular}

pulmonary edema in the emergency department showed significant improvements in breathing frequency using HFNC compared to conventional oxygen therapy (with a decrease in breathing frequency from 28.7-21.8 breaths/min for HFNC and 28.6-25.1 breaths/min for conventional oxygen therapy). ${ }^{19}$ However, there were no significant changes in the 
Table 3. Mortality Analysis Amongst Non-DNR Subjects

\begin{tabular}{|c|c|c|c|}
\hline & Alive & Died & $P$ \\
\hline Subjects, $n(\%)$ & $52(74)$ & $18(26)$ & \\
\hline Male sex, $n(\%)$ & $23(44)$ & $10(19)$ & .40 \\
\hline Age, y & $73 \pm 17$ & $74 \pm 14$ & .88 \\
\hline \multicolumn{4}{|l|}{ Medical Background* } \\
\hline Cardiovascular & $28(54)$ & $11(21)$ & .59 \\
\hline Respiratory & $10(19)$ & $5(10)$ & .51 \\
\hline Hypertension & $28(54)$ & $14(27)$ & .07 \\
\hline Diabetes mellitus & $18(35)$ & $8(15)$ & .45 \\
\hline Malignancy & $6(12)$ & $4(8)$ & .26 \\
\hline Active smoker & $8(15)$ & $3(6)$ & $>.99$ \\
\hline \multicolumn{4}{|l|}{ Etiology of Respiratory Failure* } \\
\hline Pneumonia & $33(63)$ & $12(23)$ & .80 \\
\hline Congestive heart failure & $13(25)$ & $2(4)$ & .32 \\
\hline Malignancy & $2(4)$ & $3(6)$ & .10 \\
\hline Sepsis & $11(21)$ & $5(10)$ & .53 \\
\hline COPD & $3(6)$ & $2(4)$ & .59 \\
\hline Other lung disease & $3(6)$ & $1(2)$ & $>.99$ \\
\hline \multicolumn{4}{|l|}{ Vital Signs and Physical Data } \\
\hline $\mathrm{CO}_{2}$ retention & $17(33)$ & $6(12)$ & .91 \\
\hline Fever & $13(25)$ & $5(10)$ & $>.99$ \\
\hline Bacteremia & $4(8)$ & $3(6)$ & .24 \\
\hline Pulse before HFNC & $94 \pm 22$ & $96 \pm 22$ & .75 \\
\hline Systolic before HFNC & $117 \pm 25$ & $117 \pm 30$ & .97 \\
\hline Diastolic before HFNC & $67 \pm 13$ & $66 \pm 18$ & .82 \\
\hline Breathing frequency before HFNC & $29 \pm 11$ & $31 \pm 5$ & .29 \\
\hline $\mathrm{S}_{\mathrm{pO}_{2}}$ before HFNC & $88 \pm 9$ & $83 \pm 12$ & .29 \\
\hline Visual analog scale before HFNC & $7(5.5-9)$ & $8(6-10)$ & .25 \\
\hline$\Delta$ Pulse & $-4 \pm 13$ & $-3 \pm 14$ & .71 \\
\hline$\Delta$ Systolic blood pressure & $1 \pm 16$ & $1 \pm 14$ & .90 \\
\hline$\Delta$ Diastolic blood pressure & $-0.6 \pm 16$ & $4 \pm 13$ & .36 \\
\hline$\Delta$ Breathing frequency & $-7 \pm 8$ & $-2 \pm 6$ & .067 \\
\hline$\Delta$ Oxygen saturation & $9 \pm 9$ & $9 \pm 9$ & .94 \\
\hline$\Delta$ Visual analog scale & $-2.5(-4.5$ to -1$)$ & $-2(-3$ to 0$)$ & .45 \\
\hline \multicolumn{4}{|l|}{ Treatment and Hospitalization } \\
\hline Initial $\mathrm{F}_{\mathrm{IO}_{2}}$ & $0.72 \pm 0.22$ & $0.80 \pm 0.19$ & .16 \\
\hline Initial gas flow, L/min & $46 \pm 8$ & $48 \pm 9$ & .35 \\
\hline Duration of treatment, $\mathrm{h}$ & $87 \pm 110$ & $62 \pm 118$ & .42 \\
\hline Length of stay, d & $29 \pm 36$ & $17 \pm 14$ & .045 \\
\hline Time from admission to treatment, $\mathrm{d}$ & $5 \pm 6$ & $10 \pm 10$ & .09 \\
\hline Treatment to discharge/death & $24 \pm 34$ & $7 \pm 8$ & .002 \\
\hline
\end{tabular}

This is a comparison of demographic, physiologic, and treatment parameters according to survival status for the 70 subjects without a do not resuscitate order. Data are presented as mean \pm SD, frequency (\%), or median (interquartile range).

* Overlap exists between etiologies.

HFNC $=$ high-flow nasal cannula

$\Delta=$ difference between first and second measurement

admission rate, length of stay in the emergency department and hospital, use of noninvasive ventilation, intubation, or mortality. In a non-ICU study in 67 subjects, similar clinical improvements were achieved for $68.7 \%$ of subjects, with low mortality (7.5\%) and ICU admission (4.5\%)..$^{20}$ This study demonstrated that administration of HFNC to subjects outside the ICU with hypoxemia/dyspnea led to improved breath- ing frequency and heart rate, as well as improved oxygen saturation. However, in contrast to our study, end-of-life patients, patients with a contraindication to positive-pressure ventilation, and patients in high-dependence units were excluded. ${ }^{20}$ Our study included subjects meeting all of these criteria, which may explain the poorer outcomes. Indeed, one of the interesting findings in our study was the widespread 


\section{HFNC OUTSIDE THE ICU}

Table 4. Comparison of Subjects Grouped by Improved Visual Analog Scale Score

\begin{tabular}{|c|c|c|c|c|c|}
\hline & \multirow{2}{*}{$\begin{array}{l}\text { Unimproved Visual Analog } \\
\text { Scale Score }\end{array}$} & \multirow{2}{*}{$\begin{array}{l}\text { Improved Visual Analog } \\
\text { Scale Score }\end{array}$} & \multirow{2}{*}{$P$} & \multicolumn{2}{|c|}{ Multivariate Analysis } \\
\hline & & & & Odds Ratio $(95 \% \mathrm{CI})$ & $P$ \\
\hline Subjects, $n(\%)$ & $62(56)$ & $49(44)$ & & & \\
\hline Male sex, $n(\%)$ & $30(48)$ & $25(51)$ & .78 & & \\
\hline Age, y & $73 \pm 15$ & $77 \pm 18$ & .24 & & \\
\hline \multicolumn{6}{|l|}{ Medical Background* } \\
\hline Cardiovascular & $33(53)$ & $32(65)$ & .19 & & \\
\hline Respiratory & $12(19)$ & $18(36)$ & .041 & $3.52(1.27-9.72)$ & .01 \\
\hline Hypertension & $36(58)$ & $31(63)$ & .50 & & \\
\hline Diabetes mellitus & $26(41)$ & $15(30)$ & .21 & & \\
\hline Malignancy & $11(17)$ & $10(20)$ & .72 & & \\
\hline Active smoker & $7(11)$ & $9(18)$ & .29 & & \\
\hline Do not resuscitate order & $25(40)$ & $16(32)$ & .4 & & \\
\hline \multicolumn{6}{|l|}{ Etiology of Respiratory Failure* } \\
\hline Pneumonia & $37(59)$ & $29(59)$ & .95 & & \\
\hline Congestive heart failure & $13(20)$ & $12(24)$ & .65 & & \\
\hline Malignancy & $11(17)$ & $7(14)$ & .62 & & \\
\hline Sepsis & $15(24)$ & $10(20)$ & .63 & & \\
\hline COPD & $0(0)$ & $5(10)$ & .01 & & \\
\hline Other lung disease & $4(6)$ & $4(8)$ & .73 & & \\
\hline \multicolumn{6}{|l|}{ Vital Signs and Physical Data } \\
\hline $\mathrm{CO}_{2}$ retention & $18(29)$ & $17(34)$ & .35 & & \\
\hline Fever & $18(29)$ & $9(19)$ & .21 & & \\
\hline Bacteremia & $7(11)$ & $2(4)$ & .17 & & \\
\hline Pulse before HFNC & $99 \pm 22$ & $96 \pm 24$ & .56 & & \\
\hline Systolic before HFNC & $118 \pm 28$ & $122 \pm 24$ & .45 & & \\
\hline Diastolic before HFNC & $67 \pm 17$ & $69 \pm 13$ & .62 & & \\
\hline Breathing frequency before HFNC & $29 \pm 8$ & $32 \pm 11$ & .22 & & \\
\hline $\mathrm{S}_{\mathrm{pO}_{2}}$ before $\mathrm{HFNC}$ & $85 \pm 10$ & $82 \pm 14$ & .24 & & \\
\hline Visual analog scale before & $6.5(6-8)$ & $8.0(8-9)$ & $<.001$ & $1.75(1.35-2.28)$ & $<.001$ \\
\hline$\Delta$ Pulse & $-3 \pm 13$ & $-7 \pm 14$ & .09 & & \\
\hline$\Delta$ Systolic blood pressure & $-5 \pm 17$ & $1 \pm 16$ & .07 & & \\
\hline$\Delta$ Diastolic blood pressure & $-1 \pm 16$ & $0 \pm 12$ & .76 & & \\
\hline$\Delta$ Breathing frequency & $-3 \pm 5$ & $-7 \pm 8$ & .030 & & \\
\hline$\Delta$ Oxygen saturation & $7 \pm 8$ & $12 \pm 14$ & .01 & & \\
\hline$\Delta$ Visual analog scale & $-1 \pm 1$ & $-5 \pm 1$ & $<.01$ & & \\
\hline \multicolumn{6}{|l|}{ Treatment and Hospitalization } \\
\hline Initial $\mathrm{F}_{\mathrm{IO}_{2}}$ & $0.78 \pm 0.21$ & $0.74 \pm 0.20$ & .26 & & \\
\hline Initial gas flow, $\mathrm{L} / \mathrm{min}$ & $45 \pm 10$ & $47 \pm 9$ & .19 & & \\
\hline Duration of HFNC, $\mathrm{h}$ & $81 \pm 116$ & $100 \pm 122$ & .41 & & \\
\hline Length of stay, d & $25 \pm 16$ & $20 \pm 15$ & .41 & & \\
\hline Admission to HFNC, d & $7 \pm 10$ & $7 \pm 10$ & .85 & & \\
\hline HFNC to discharge, $\mathrm{d}$ & $17 \pm 32$ & $13 \pm 11$ & .35 & & \\
\hline $\begin{array}{l}\text { Data are presented as mean } \pm \mathrm{SD} \text {, frequency }(\%), \\
\text { * Overlap exists between etiologies. } \\
\text { HFNC = high-flow nasal cannula } \\
\Delta=\text { difference between first and second measurem }\end{array}$ & nedian (interquartile range). & & & & \\
\hline
\end{tabular}

use of HFNC among DNR subjects. In this population, HFNC was found to be equally effective at reducing dyspnea compared to the non-DNR population. Shortness of breath and respiratory difficulties are major and distressing symptoms at the end of life, ${ }^{21-24}$ and HFNC may have a significant role in alleviating suffering, ${ }^{22,23}$ possibly with an opiate-sparing effect. $^{24}$

When treating hypoxemic respiratory failure with modalities other than intubation and invasive mechanical ventilation, there is a safety issue that needs to be ad- 
Table 5. Comparison of Subjects Grouped by DNR Order Status

\begin{tabular}{|c|c|c|c|}
\hline & DNR Order & No DNR Order & $P$ \\
\hline Subjects, $n(\%)$ & $41(37)$ & $70(63)$ & \\
\hline Male sex, $n(\%)$ & $22(54)$ & $33(47)$ & .51 \\
\hline Age, y & $76 \pm 18$ & $74 \pm 16$ & .45 \\
\hline \multicolumn{4}{|l|}{ Medical Background* } \\
\hline Cardiovascular & $23(56)$ & $39(56)$ & .43 \\
\hline Respiratory & $15(37)$ & $15(21)$ & .08 \\
\hline Hypertension & $25(61)$ & $42(60)$ & .92 \\
\hline Diabetes mellitus & $15(37)$ & $26(37)$ & .95 \\
\hline Malignancy & $11(27)$ & $10(14)$ & .10 \\
\hline Active smoker & $5(12)$ & $11(16)$ & .61 \\
\hline $\mathrm{CO}_{2}$ retention & $12(32)$ & $23(34)$ & .84 \\
\hline \multicolumn{4}{|l|}{ Etiology of Respiratory Failure* } \\
\hline Pneumonia & $21(51)$ & $45(64)$ & .18 \\
\hline Congestive heart failure & $10(24)$ & $15(21)$ & .72 \\
\hline Malignancy & $13(32)$ & $5(7)$ & $<.001$ \\
\hline Sepsis & $9(22)$ & $16(23)$ & .91 \\
\hline COPD & $0(0)$ & $5(7)$ & .15 \\
\hline Other lung disease & $4(10)$ & $4(6)$ & .46 \\
\hline \multicolumn{4}{|l|}{ Vital Signs and Physical Data } \\
\hline Fever & $9(22)$ & $18(26)$ & .63 \\
\hline Bacteremia & $2(6)$ & $7(11)$ & .66 \\
\hline Pulse before HFNC & $102 \pm 23$ & $95 \pm 22$ & .13 \\
\hline Systolic before HFNC & $125 \pm 26$ & $117 \pm 26$ & .14 \\
\hline Diastolic before HFNC & $70 \pm 17$ & $67 \pm 14$ & .27 \\
\hline Breathing frequency before HFNC & $33 \pm 9$ & $29 \pm 10$ & .19 \\
\hline $\mathrm{S}_{\mathrm{pO}_{2}}$ before $\mathrm{HFNC}$ & $82 \pm 15$ & $85 \pm 10$ & .29 \\
\hline Visual analog scale before HFNC & $8(6-9)$ & $8(6-9)$ & .36 \\
\hline$\Delta$ Pulse & $-6 \pm 15$ & $-4 \pm 13$ & .50 \\
\hline$\Delta$ Systolic blood pressure & $-9 \pm 18$ & $1 \pm 15$ & .01 \\
\hline$\Delta$ Diastolic blood pressure & $-2 \pm 11$ & $0 \pm 15$ & .44 \\
\hline$\Delta$ Breathing frequency & $-6 \pm 6$ & $-6 \pm 8$ & .92 \\
\hline$\Delta$ Oxygen saturation & $10 \pm 14$ & $9 \pm 9$ & .52 \\
\hline$\Delta$ Visual analog scale & $-2(-3.5$ to -1.0$)$ & $-2(-4$ to -1$)$ & .49 \\
\hline \multicolumn{4}{|l|}{ Treatment and Hospitalization } \\
\hline Initial $\mathrm{F}_{\mathrm{IO}_{2}}$ & $0.80 \pm 0.21$ & $0.74 \pm 0.21$ & .11 \\
\hline Initial gas flow, $\mathrm{L} / \mathrm{min}$ & $45 \pm 9$ & $46 \pm 8$ & .74 \\
\hline Duration of HFNC, h & $104 \pm 128$ & $81 \pm 112$ & .33 \\
\hline Length of stay, d & $18 \pm 19$ & $26 \pm 32$ & .10 \\
\hline Admission to HFNC, $\mathrm{d}$ & $9 \pm 14$ & $6 \pm 7$ & .33 \\
\hline HFNC to discharge, $\mathrm{d}$ & $9 \pm 9$ & $20 \pm 30$ & .01 \\
\hline $\begin{array}{l}\text { Data are presented as mean } \pm \mathrm{SD} \text {, frequency }(\%) \text {, } \\
* \text { Overlap exists between etiologies. } \\
\text { DNR }=\text { do not resuscitate order } \\
\mathrm{HFNC}=\text { high-flow nasal cannula } \\
\Delta=\text { difference between first and second measuren }\end{array}$ & & & \\
\hline
\end{tabular}

dressed. Numerous studies have demonstrated that delaying intubation in patients who are not doing well on noninvasive methods of oxygenation (eg, noninvasive ventilation or HFNC) may lead to worse outcomes. 1,25,26 Administering HFNC outside the ICU with minimal monitoring may delay timely airway intervention and intubation. However, we did not find a difference between the mortality of non-DNR subjects in this study and the mortality in other similar population cohorts. ${ }^{27}$

Our study has several limitations. Because this was an observational study, there was no control group for outcome comparison, although overall reported mortality for internal medicine department admissions is similar; eg, among 10,788 hospitalized patients in a 3.5-y period, $874(8.1 \%)$ 


\section{HFNC OUTSIDE THE ICU}

died during their admission. ${ }^{27}$ Study forms were completed for only 111 subjects out of the 176 subjects treated with HFNC, which could suggest a bias. This difference is most likely due to the fact that data collection was not performed reliably on weekends. Comparison of basic demographics between included subjects and subjects with inclusion criteria who were not part of the final analysis revealed that the populations were similar. Another limitation is that the number of analyzed subjects (ie, 111) did not reach the predetermined sample size of 120 subjects. However, even if 9 additional subjects were included and reported no benefit from therapy, the result would remain statistically significant because 90 of the 120 subjects would have reported improvement (75\%), 95\% CI 66-82, $P<.001)$. Another limitation is that HFNC use was not protocolized, and many subjects received flows below the maximal flow of $60 \mathrm{~L} / \mathrm{min}$. HFNC parameters were set at the bedside by the respiratory therapist according to the clinical condition and the comfort of the subject. Further, gas flow was not a predictor of success in any of the analyses. Finally, the visual analog scale and physiological follow-up were limited to the observations immediately prior to and 30 min after administration of HFNC.

\section{Conclusion}

The use of HFNC therapy in the ward setting was effective, being associated with significantly improved comfort and physiological parameters. Overall mortality in non-DNR subjects was similar to that reported by others for similar hospital admissions. In addition, the therapy was used widely and effectively in DNR subjects, for whom there may be a beneficial palliative effect.

\section{REFERENCES}

1. Frat JP, Thille AW, Mercat A, Girault C, Ragot S, Perbet S, et al. High-flow oxygen through nasal cannula in acute hypoxemic respiratory failure. N Engl J Med 2015;372(23):2185-2196.

2. Lenglet H, Sztrymf B, Leroy C, Brun P, Dreyfuss D, Ricard JD. Humidified high flow nasal oxygen during respiratory failure in the emergency department: feasibility and efficacy. Respir Care 2012; 57(11):1873-1878.

3. Delorme M, Bouchard PA, Simon M, Simard S, Lellouche F. Effects of high-flow nasal cannula on the work of breathing in patients recovering from acute respiratory failure. Crit Care Med 2017;45(12): 1981-1988.

4. Leeies M, Flynn E, Turgeon AF, Paunovic B, Loewen H, Rabbani R, et al. High-flow oxygen via nasal cannulae in patients with acute hypoxemic respiratory failure: a systematic review and meta-analysis. Syst Rev 2017;6(1):202.

5. Messika J, Ben Ahmed K, Gaudry S, Miguel-Montanes R, Rafat C, Sztrymf B, et al. Use of high-flow nasal cannula oxygen therapy in subjects with ARDS: a 1-year observational study. Respir Care 2015; 60(2): 162-169.

6. Frat JP, Coudroy R, Marjanovic N, Thille AW. High-flow nasal oxygen therapy and noninvasive ventilation in the management of acute hypoxemic respiratory failure. Ann Transl Med 2017;5(14):297.
7. Lepere V, Messika J, La Combe B, Ricard JD. High-flow nasal cannula oxygen supply as treatment in hypercapnic respiratory failure. Am J Emerg Med 2016;34(9):1914.

8. Nishimura M. High-flow nasal cannula oxygen therapy in adults. J Intensive Care 2015;3(1):15.

9. Roca O, Hernandez G, Diaz-Lobato S, Carratala JM, Gutierrez RM, Masclans JR. Current evidence for the effectiveness of heated and humidified high flow nasal cannula supportive therapy in adult patients with respiratory failure. Crit Care 2016;20(1):109.

10. Sztrymf B, Messika J, Bertrand F, Hurel D, Leon R, Dreyfuss D, et al. Beneficial effects of humidified high flow nasal oxygen in critical care patients: a prospective pilot study. Intensive Care Med 2011; 37(11):1780-1786.

11. Ni YN, Luo J, Yu H, Liu D, Liang BM, Liang ZA. The effect of high-flow nasal cannula in reducing the mortality and the rate of endotracheal intubation when used before mechanical ventilation compared with conventional oxygen therapy and noninvasive positive pressure ventilation: a systematic review and meta-analysis. Am J Emerg Med 2018;36(2):226-233.

12. Monro-Somerville T, Sim M, Ruddy J, Vilas M, Gillies MA. The effect of high-flow nasal cannula oxygen therapy on mortality and intubation rate in acute respiratory failure: a systematic review and meta-analysis. Crit Care Med 2017;45(4):e449-e456.

13. Ni YN, Luo J, Yu H, Liu D, Ni Z, Cheng J, et al. Can high-flow nasal cannula reduce the rate of endotracheal intubation in adult patients with acute respiratory failure compared with conventional oxygen therapy and noninvasive positive pressure ventilation? A systematic review and meta-analysis. Chest 2017;151(4):764-775.

14. Lin SM, Liu KX, Lin ZH, Lin PH. Does high-flow nasal cannula oxygen improve outcome in acute hypoxemic respiratory failure? A systematic review and meta-analysis. Respir Med 2017;131: 58-64.

15. Maitra S, Som A, Bhattacharjee S, Arora MK, Baidya DK. Comparison of high-flow nasal oxygen therapy with conventional oxygen therapy and noninvasive ventilation in adult patients with acute hypoxemic respiratory failure: a meta-analysis and systematic review. J Crit Care 2016;35:138-144.

16. Zhao H, Wang H, Sun F, Lyu S, An Y. High-flow nasal cannula oxygen therapy is superior to conventional oxygen therapy but not to noninvasive mechanical ventilation on intubation rate: a systematic review and meta-analysis. Crit Care 2017;21(1):184.

17. Roca O, Messika J, Caralt B, Garcia-de-Acilu M, Sztrymf B, Ricard JD, et al. Predicting success of high-flow nasal cannula in pneumonia patients with hypoxemic respiratory failure: the utility of the ROX index. J Crit Care 2016;35:200-205.

18. Roca O, Caralt B, Messika J, Samper M, Sztrymf B, Hernandez G, et al. An index combining respiratory rate and oxygenation to predict outcome of nasal high flow therapy. Am J Respir Crit Care Med 2018.

19. Makdee O, Monsomboon A, Surabenjawong U, Praphruetkit N, Chaisirin W, Chakorn T, et al. High-flow nasal cannula versus conventional oxygen therapy in emergency department patients with cardiogenic pulmonary edema: a randomized controlled trial. Ann Emerg Med 2017;70(4):465-472.e462.

20. Pirret AM, Takerei SF, Matheson CL, Kelly M, Strickland W, Harford J, et al. Nasal high flow oxygen therapy in the ward setting: a prospective observational study. Intensive Crit Care Nurs 2017;42:127-134.

21. Booth S, Wade R, Johnson M, Kite S, Swannick M, Anderson H. The use of oxygen in the palliation of breathlessness. A report of the expert working group of the Scientific Committee of the Association of Palliative Medicine. Respir Med 2004;98(1):66-77.

22. Epstein AS, Hartridge-Lambert SK, Ramaker JS, Voigt LP, Portlock CS. Humidified high-flow nasal oxygen utilization in patients with 


\section{HFNC OUTSIDE THE ICU}

cancer at Memorial Sloan-Kettering Cancer Center. J Palliat Med 2011;14(7):835-839.

23. Peters SG, Holets SR, Gay PC. High-flow nasal cannula therapy in do-not-intubate patients with hypoxemic respiratory distress. Respir Care 2013;58(4):597-600.

24. Nava S, Ferrer M, Esquinas A, Scala R, Groff P, Cosentini R, et al. Palliative use of non-invasive ventilation in end-of-life patients with solid tumours: a randomised feasibility trial. Lancet Oncol 2013;14(3):219-227.
25. Kang BJ, Koh Y, Lim CM, Huh JW, Baek S, Han M, et al. Failure of high-flow nasal cannula therapy may delay intubation and increase mortality. Intensive Care Med 2015;41(4):623-632.

26. Rabbat A, Blanc K, Lefebvre A, Lorut C. Nasal high flow oxygen therapy after extubation: the road is open but don't drive too fast! J Thorac Dis 2016;8(12):e1620-e1624.

27. Schwartz N, Sakhnini A, Bisharat N. Predictive modeling of inpatient mortality in departments of internal medicine. Intern Emerg Med 2018;13(2):205-211.

This article is approved for Continuing Respiratory Care Education credit. For information and to obtain your CRCE

(free to AARC members) visit

www.rcjournal.com 